\title{
Determining the Source of Fugitive Dust in Lattimer, Pennsylvania
}

\author{
L. Dickson ${ }^{1, *}$, P. Griffith ${ }^{1}$, M. Maresch ${ }^{1}$, D. Molinaro ${ }^{1}$, J. Penrose ${ }^{1}$, J. Calabrese ${ }^{2}$ \\ ${ }^{1}$ Department of Geology \& Physics, Lock Haven University of Pennsylvania, Lock Haven, Pennsylvania, USA \\ ${ }^{2}$ Department of Biological Sciences, Lock Haven University of Pennsylvania, Lock Haven, Pennsylvania, USA \\ *Corresponding author: ldickson@lockhaven.edu
}

\begin{abstract}
Fugitive dust samples collected from residential properties in the village of Lattimer, Pennsylvania were analyzed for total concentrations of major and minor elements $\mathrm{Si}, \mathrm{Al}, \mathrm{Ti}, \mathrm{Fe}, \mathrm{Mg}, \mathrm{Na}, \mathrm{K}, \mathrm{C}$, and S using energy dispersive $\mathrm{x}$-ray spectrometry. Observed under high magnification, the individual dust particles are irregular-shaped with angular edges and range in size from 20 to 150 microns. Rock samples of gray to black organic-rich mudstone, shale, and siltstone units interbedded with thin layers of anthracite coal were collected next to a rock quarry operation that is suspected as a possible source of the fugitive dust. Major and minor element concentrations in the rock samples are compared to major and minor element concentrations in 150 individual dust particles. The fugitive dust and rock samples that were analyzed have Si concentrations that vary from 0.08 to 43.34 wt.\% and C concentrations that vary from 3.36 to 95.68 wt.\%. All of the major and minor element concentrations in the rock samples lie within the representative range of element concentrations in the individual dust particles. The Si and C concentrations in the fugitive dust suggest that the particles originated from a carbon-rich silicate rock source. Five of the fugitive dust particles analyzed had C concentrations in excess of $60 \mathrm{wt} . \%$ and can be considered coal dust. Results suggest that the chemical composition of the fugitive dust particles is consistent with the chemical composition of the rocks that are actively extracted and crushed at the rock quarry site located adjacent to the village of Lattimer, Pennsylvania.
\end{abstract}

Keywords: air pollution, fugitive dust, particulate matter, surface mining, quarry dust

Cite This Article: L. Dickson, P. Griffith, M. Maresch, D. Molinaro, J. Penrose, and J. Calabrese, "Determining the Source of Fugitive Dust in Lattimer, Pennsylvania." American Journal of Environmental Protection, vol. 5, no. 3 (2017): 73-77. doi: 10.12691/env-5-3-2.

\section{Introduction}

Fugitive dust is a type of fugitive particular matter (PM) that is generated from open spaces exposed to wind processes rather than from sources of combustion that have passed through a vent or stack before being released into the air. Common sources of fugitive dust are construction and demolition sites, surface mines and rock quarry sites, unpaved roads, vacant lots, and agricultural areas $[1,2]$. The fugitive dust resulting from these open area examples are composed mainly of soil and minerals that contain $\mathrm{Si}, \mathrm{Al}, \mathrm{Fe}$, and $\mathrm{Ca}$, but may also contain pollen, spores, or particles of rubber from tires $[3,4]$.

The aerodynamic diameter of fugitive dust can range in size from 0.005 to $100 \mu \mathrm{m}$ [5]. Fugitive dust typically originates and remains at or near ground level where its impact on the surrounding environment and human health is greatest [6]. While airborne, fugitive dust can reduce visibility causing potential hazards for traffic. After the dust has settled, it poses a nuisance by coating homes, yards, and businesses.

The inhalation of the respirable fraction of fugitive dust, particularly $\mathrm{PM}_{10}$ and $\mathrm{PM}_{2.5}$ that refers to $\mathrm{PM}$ with an aerodynamic diameter of $<10 \mu \mathrm{m}$ and $<2.5 \mu \mathrm{m}$, respectively, is linked to aggravated asthma, chronic bronchitis, and premature death $[7,8,9]$. Inhalation of $\mathrm{PM}_{10}$ can reach the upper part of the airway and lung, and inhalation of $\mathrm{PM}_{2.5}$ can penetrate deeply into the lungs and cause adverse effects on human health $[10,11]$. Larger fugitive dust particles settle more rapidly and may cause irritation to the upper respiratory tract and the eyes. Fugitive dust from geologic materials pose a threat to human health due to the presence of crystalline silica [12]. Fugitive dust from sources of sedimentary rocks that are interbedded with coal units present a specific hazard of respiratory illness and lung damage due to both crystalline silica and high carbon content [13,14].

In June, 2012, residents of Lattimer, Pennsylvania began to issue complaints to local and state officials about anomalous amounts of black dust accumulating on surfaces around their homes and yards, and entering their homes through windows and doors. The residents suspected that the fugitive dust originated from a nearby rock quarry that had recently installed a new rock crusher on the premises. Witnesses reported observing dark clouds of airborne dust when the rock crusher was in use and complained that the quarry owners should install and maintain specified equipment to capture and control the fugitive emissions.

Rocks quarried from the site are Llewellyn Formation and described as gray to black organic-rich mudstone, 
shale, and siltstone units that are interbedded with thin layers of anthracite coal [15].

The present study was to collect rock and fugitive dust samples for chemical and morphological analysis. The goal was to determine if the chemical composition and morphology of fugitive dust found on outdoor surfaces in the village of Lattimer corresponds to the chemical composition and morphology of rocks that represent the Llewellyn Formation. The results of this study would provide useful evidence in determining the source of the fugitive dust, and more specifically, determine if the nearby rock quarry is a probable source.

\section{Methodology}

\subsection{Study Area}

Lattimer is a small village located at $40^{\circ} 59^{\prime} 38^{\prime \prime} \mathrm{N}$, 75'57'40"W in Hazle Township, Luzerne County, Pennsylvania with a population of approximately 554 people. A rock quarry located to the north of the village extends approximately $2.5 \mathrm{~km}$ in length and varies in width from $0.25 \mathrm{~km}$ to $0.5 \mathrm{~km}$. The entire expanse of the rock quarry is visible in the satellite image provided in Figure 1 . The southern boundary of the rock quarry is 120 meters from the closest residential property.

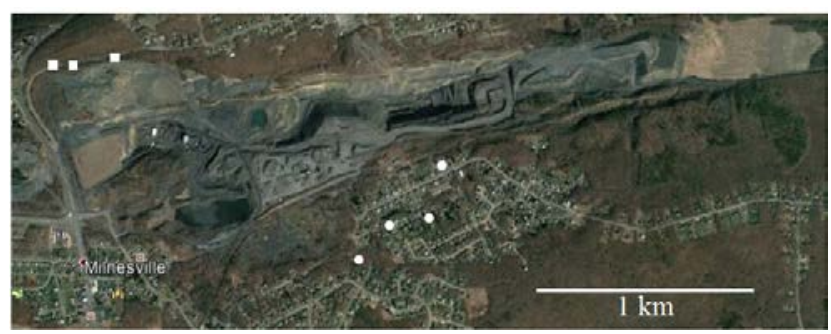

Figure 1. Satellite image of the village of Lattimer (center) and the rock quarry located to the north of Lattimer. Fugitive dust sampling locations at four residential properties are indicated with white circles and rock sampling locations are indicated with white squares

\subsection{Sampling}

Fifty-two fugitive dust samples were collected from level outdoor surfaces at four residential properties in the village of Lattimer. Sampling locations are indicated by white circles in the satellite image provided in Figure 1. Pelco aluminum specimen mounts affixed with doublesided carbon adhesive tabs were pressed directly onto the dust-covered surfaces to obtain samples for analysis. The specimen mounts were placed in Pelco specimen storage boxes immediately after sampling. Care was taken to collect dust samples from smooth vinyl, plastic, or metal surfaces such as fence railings, flat window sills, lamp posts, and outdoor tables to minimize the potential of collecting particles that are inherent to the surface material. For example, thick accumulations of fugitive dust on building stone façades were documented and photographed (Figure 2), but not sampled to avoid contamination by mineral grains contained in the stone façade.

Rock samples identified as Llewellyn Formation were collected from rock outcrops along the road adjacent to the quarry property on the northwest side (Figure 1). The rocks were gray to black organic-rich mudstone, shale, and siltstone. Thin layers of anthracite coal were observed in the shale rocks. Each rock sample was bagged, labeled, and geographically referenced using GPS. Chip fragments were broken from each rock and placed on Pelco aluminum specimen mounts affixed with double-sided carbon adhesive tabs for analysis.

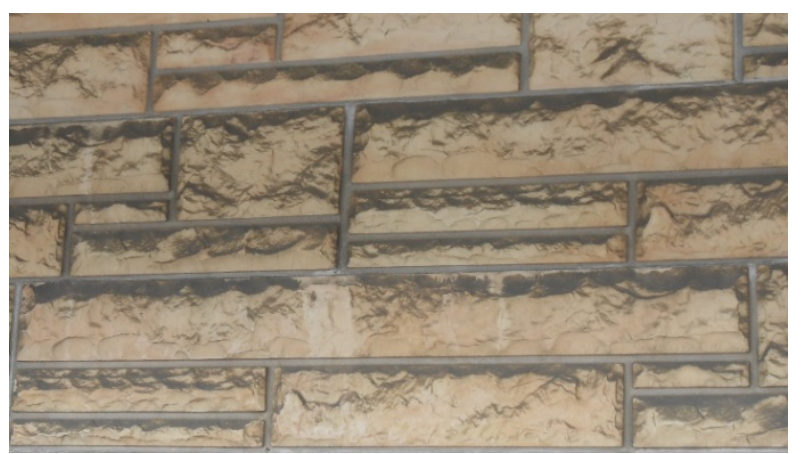

Figure 2. Lattimer building stone façade with thick accumulation of black dust

\subsection{SEM/EDX Analysis}

Fugitive dust samples and rock samples were analyzed using a Tescan Scanning Electron Microscope (SEM) with an Oxford Instruments Energy Dispersive X-ray Spectrometer (EDS). The samples were studied using an electron beam with a $20 \mathrm{kV}$ accelerating voltage, a $15-\mathrm{mm}$ working distance, and a wide range of 400 to 3,500-times magnification. The chemical composition, size parameters, and morphology were examined. A total of 150 individual dust particles and seven rock samples of the Llewellyn Formation were analyzed for major and minor elements $\mathrm{Si}$, Al, Ti, Fe, Mg, Na, K, C, and S.

\section{Results and Discussion}

Individual dust particles observed at high magnification using the SEM are irregular in shape with angular sides and corners (Figure 3). The diameter of 70 individual dust particles were measured from SEM images viewed using the scale and measurement feature in the NIH ImageJ software program [16]. Measurement of individual particles indicate a range in particle size from 20 to 150 $\mu \mathrm{m}$. The individual dust particles analyzed for major and minor elements ranged in particle size from 30 to $150 \mu \mathrm{m}$ with an average particle size of $80 \mu \mathrm{m}$.

Chemical analyses results for major and minor element concentrations in individual particles of fugitive dust are listed in Table 1 . The results are listed as the range of element concentrations in dust particles collected at four residential properties. Data is reported in weight\% for each element. Chemical analyses for major and minor element concentrations in individual dust particles show a wide range in $\mathrm{Si}, \mathrm{Al}, \mathrm{Fe}, \mathrm{K}, \mathrm{C}$, and $\mathrm{S}$ concentrations and a narrow range in $\mathrm{Ti}, \mathrm{Mg}$, and $\mathrm{Na}$ concentrations.

The fugitive dust particles analyzed have Si concentrations that vary from 0.08 to 43.34 wt.\%. $\mathrm{Al}$ and Fe concentrations in the fugitive dust particles vary from 0.08 to 16.40 wt.\% and 0.11 to 39.97 wt.\%, respectively. Ti concentrations in most of the fugitive dust particles lie in a narrow range 
between 0.06 to 4.24 wt.\%. Eleven of the individual dust particles have higher Ti concentrations that vary from 6.98 and 48.92 wt.\%. Similarly, Mg concentrations in most of the fugitive dust particles lie in a narrow range between 0.08 to 1.61 wt.\%. Five of the individual dust particles have higher $\mathrm{Mg}$ concentrations that vary from 5.84 to 10.07 wt.\%. Na and $\mathrm{K}$ concentrations in the fugitive dust particles vary from 0.11 to 4.78 wt.\% and 0.09 to 6.58 wt.\%, respectively. C concentrations in the fugitive dust particles show the widest range from 3.36 to 95.83 wt.\% and S concentrations vary from 0.06 to 1.86 wt.\%.

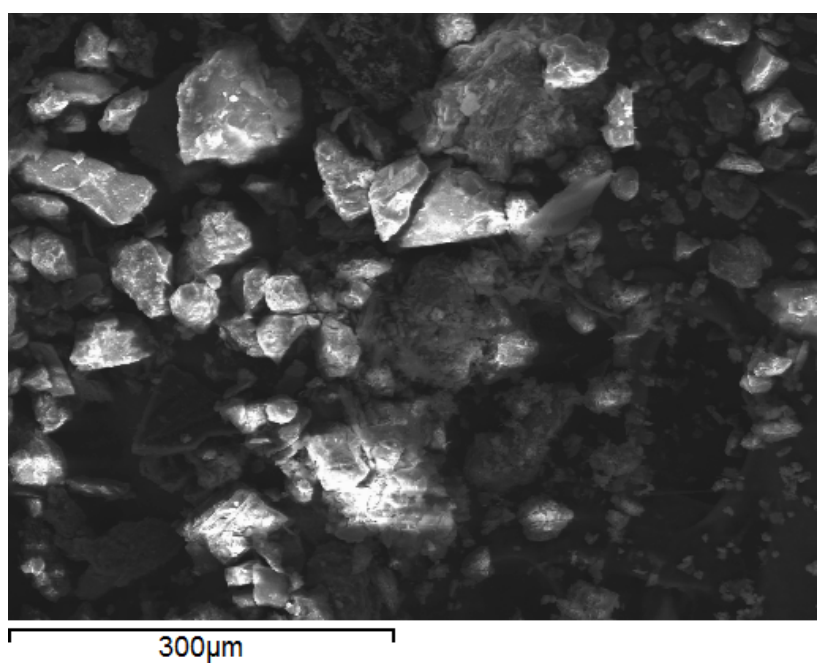

Figure 3. Scanning electron microscope image showing irregular-shaped, angular fugitive dust particles that range in size from 20 to $150 \mu \mathrm{m}$

Table 1. Chemical Analysis Results for Major and Minor Element Concentrations in Individual Particles of Fugitive Dust

\begin{tabular}{|c|c|c|c|c|}
\hline Sample & BR1-BR21 & SR1-SR46 & EB1-EB42 & PO1-PO41 \\
\hline $\mathrm{n}$ & 21 & 46 & 42 & 41 \\
\hline $\mathrm{Si}$ & $1.44-29.22$ & $0.08-40.02$ & $3.01-36.94$ & $0.78-43.34$ \\
\hline $\mathrm{Al}$ & $0.76-8.47$ & $0.08-14.77$ & $0.45-12.94$ & $0.17-16.40$ \\
\hline $\mathrm{Ti}$ & $0.13-0.63$ & $0.06-3.67$ & $0.09-28.01$ & $0.14-48.92$ \\
\hline $\mathrm{Fe}$ & $0.42-2.88$ & $0.11-9.50$ & $0.29-12.33$ & $0.17-39.97$ \\
\hline $\mathrm{Mg}$ & $0.13-0.52$ & $0.08-10.07$ & $0.08-1.41$ & $0.13-7.99$ \\
\hline $\mathrm{Na}$ & $0.14-0.34$ & $0.11-0.57$ & $0.14-4.00$ & $0.11-4.78$ \\
\hline $\mathrm{K}$ & $0.18-2.49$ & $0.09-5.57$ & $0.15-6.39$ & $0.12-6.58$ \\
\hline $\mathrm{C}$ & $11.01-58.53$ & $7.67-95.83$ & $7.33-50.79$ & $3.36-81.41$ \\
\hline $\mathrm{S}$ & $0.10-0.84$ & $0.06-0.42$ & $0.10-1.12$ & $0.13-1.86$ \\
\hline
\end{tabular}

Chemical analysis results for major and minor element concentrations in the rock samples are listed in Table 2. Data is reported in weight\% for each element. The results show that one carbonaceous shale sample is high in $\mathrm{C}$ (95.68 wt.\%) and S (0.62 wt.\%) concentrations, and low in $\mathrm{Si}(0.10$ wt.\%) and $\mathrm{Al}(0.10$ wt.\%) concentrations. All other rock samples are classified as organic-rich shale with low to intermediate $\mathrm{C}$ concentrations that range from 11.28 to 27.87 wt.\% and zero to low S concentrations, compared to the carbonaceous shale sample. The organic-rich shale rock samples have intermediate $\mathrm{Si}$ concentrations that range from 12.53 to 19.02 wt.\% and are high in $\mathrm{Al}$ concentrations that range from 8.42 to 12.45 wt.\%. All of the major and minor element concentrations in the shale rock samples correspond to the representative range of elements in the fugitive dust particles.
Table 2. Chemical Analysis Results for Major and Minor Element Concentrations in Llewellyn Formation Rock Samples.

\begin{tabular}{|c|c|c|c|c|c|c|c|}
\hline Sample & LFm1 & LFm2 & LFm3 & LFm4 & LFm5 & LFm6 & LFm7 \\
\hline $\mathrm{Si}$ & 0.10 & 14.02 & 12.53 & 17.48 & 19.02 & 16.25 & 16.87 \\
\hline $\mathrm{Al}$ & 0.10 & 9.51 & 9.08 & 11.05 & 12.45 & 8.42 & 9.17 \\
\hline $\mathrm{Ti}$ & --- & 0.51 & 0.40 & 0.86 & 1.08 & 0.44 & 0.39 \\
\hline $\mathrm{Fe}$ & --- & 1.43 & 1.34 & 1.11 & 1.32 & 6.63 & 5.37 \\
\hline $\mathrm{Mg}$ & --- & 0.31 & 0.21 & 0.41 & 0.39 & 0.73 & 0.61 \\
\hline $\mathrm{Na}$ & --- & 0.18 & --- & 0.16 & --- & 0.14 & 0.19 \\
\hline $\mathrm{K}$ & --- & 2.58 & 2.14 & 3.57 & 4.44 & 2.11 & 2.51 \\
\hline $\mathrm{C}$ & 95.68 & 25.82 & 27.87 & 14.72 & 11.28 & 14.89 & 13.45 \\
\hline $\mathrm{S}$ & 0.62 & 0.13 & 0.10 & --- & --- & --- & -- \\
\hline
\end{tabular}

Chemical data for major and minor element concentrations in the fugitive dust particles and the Llewellyn Formation rock samples are illustrated in chemical plots shown in Figure 4 through Figure 11. Chemical plots were generated using the IgPet computer software program [17]. Each element analyzed is plotted against wt.\% Si for comparative purposes. All samples analyzed contained $\mathrm{Si}$, but some of the individual dust particles did not contain all elements of interest. For example, the dust particles that exhibited the highest concentrations of Si (greater than 30 wt.\%) did not contain $\mathrm{Ti}, \mathrm{Na}$, or S. Chemical data for the fugitive dust particles produce a predominant trend in each chemical plot.

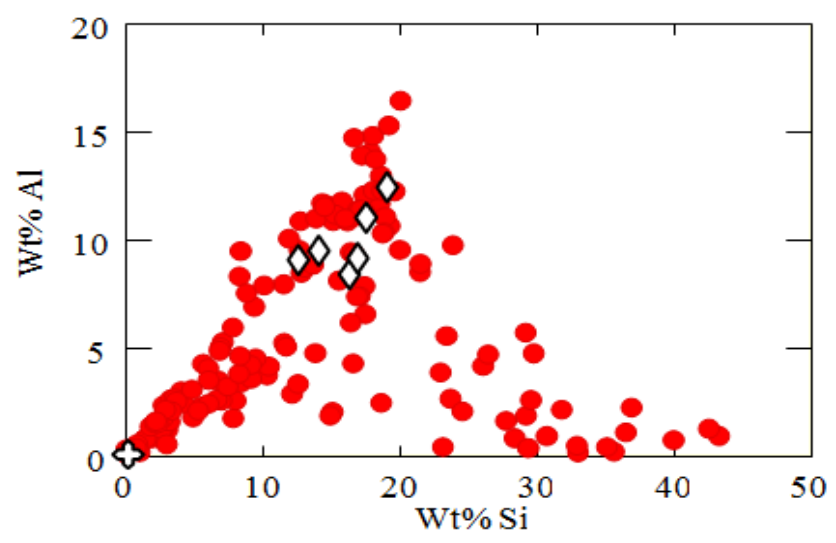

Figure 4. Chemical analyses for wt.\% $\mathrm{Al}$ in fugitive dust particles (red circles), shale rock samples (white diamonds), and carbonaceous shale (white star) plotted against wt.\% Si

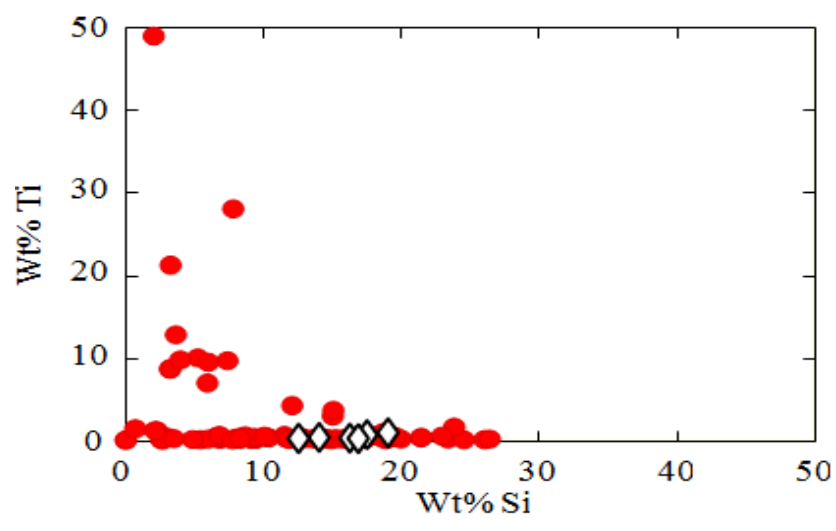

Figure 5. Chemical analyses for wt.\% $\mathrm{Ti}$ in fugitive dust particles (red circles) and shale samples (white diamonds) plotted against wt.\% Si 


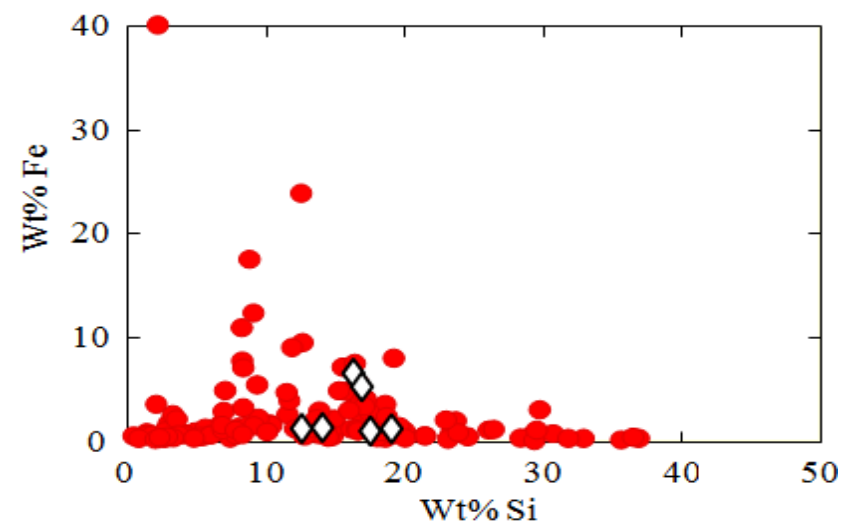

Figure 6. Chemical analyses for wt.\% Fe in fugitive dust particles (red circles) and shale samples (white diamonds) plotted against wt.\% Si

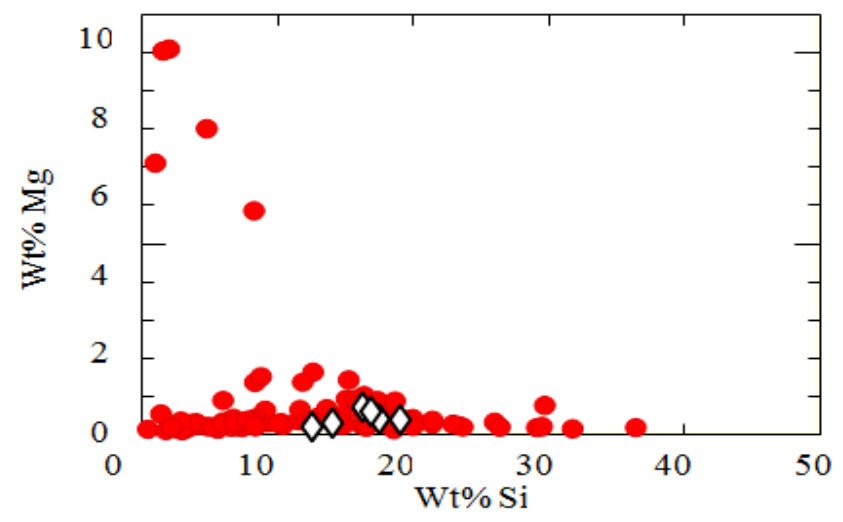

Figure 7. Chemical analyses for wt.\% Mg in fugitive dust particles (red circles) and shale samples (white diamonds) plotted against wt.\% Si

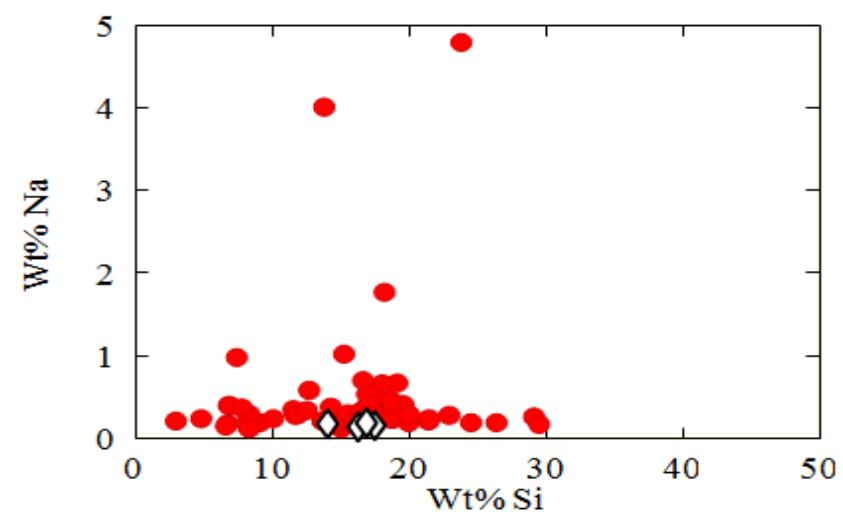

Figure 8. Chemical analyses for wt.\% Na in fugitive dust particles (red circles) and shale samples (white diamonds) plotted against wt.\% Si

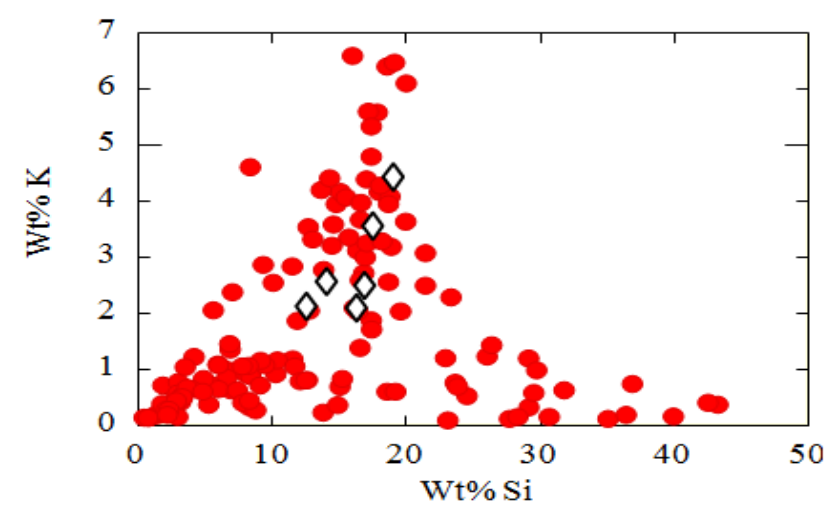

Figure 9. Chemical analyses for wt.\% K in fugitive dust particles (red circles) and shale samples (white diamonds) plotted against wt.\% Si
$\mathrm{Si}, \mathrm{Al}, \mathrm{Ti}, \mathrm{Fe}, \mathrm{Mg}, \mathrm{Na}$, and $\mathrm{K}$ concentrations in the fugitive dust particles and the rock samples are consistent with characteristic element concentrations found in mudstone, shale, and siltstone rocks $[18,19]$. The variable concentrations of $\mathrm{C}$ in the rock samples are indicative of the organic-rich nature of the rocks (Figure 10). Not surprisingly, the carbonaceous shale sample interbedded with thin layers of anthracite coal had a $\mathrm{C}$ concentration in excess of 95 wt.\% and the highest S concentration of 0.62 wt.\%. Five of the fugitive dust particles analyzed had C concentrations in excess of 60 wt.\% and can therefore be considered as coal dust (Figure 10).

Chemical data for the rock samples lie within the predominant trend produced by the chemical data for the fugitive dust particles in each chemical plot of wt.\% element. The overlap in chemical data strongly suggests a similar composition between the fugitive dust particles and the rocks analyzed.

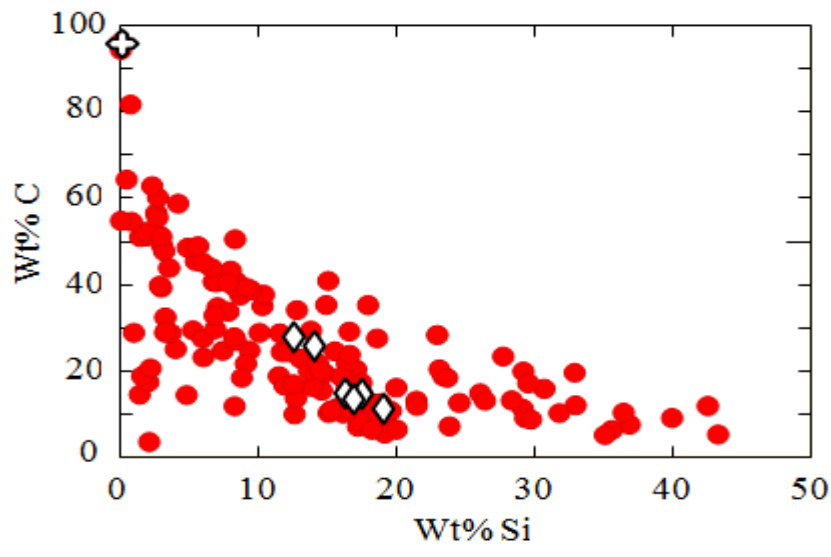

Figure 10. Chemical analyses for wt.\% C in fugitive dust particles (red circles), shale rock samples (white diamonds), and carbonaceous shale (white star) plotted against wt.\% Si

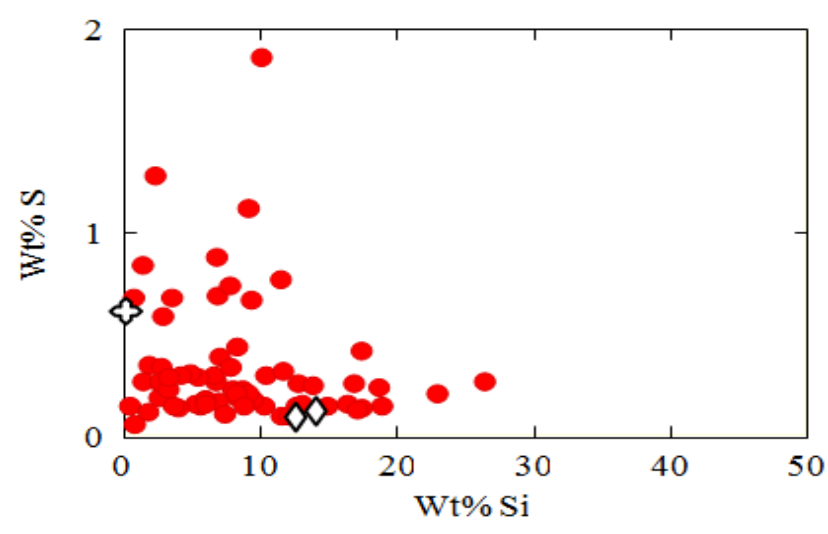

Figure 11. Chemical analyses for wt.\% $\mathrm{S}$ in fugitive dust particles (red circles), shale rock samples (white diamonds), and carbonaceous shale (white star) plotted against wt.\% Si

\section{Conclusions}

Fugitive dust particles observed under high magnification are irregular-shaped with angular corners and edges. These observations are consistent with fugitive dust particle morphology expected from rock quarrying and crushing activities that generate angular shards and fragmented particles. The Si and C concentrations in the 
fugitive dust suggest that the particles originated from a carbon-rich silicate rock source. Major and minor element concentrations of the individual dust particles are consistent with mudstone, shale, and siltstone compositions and produce predominant trends of data on chemical plots of wt.\% elements. Major and minor element concentrations of the rock samples identified as Llewellyn Formation organic-rich mudstone, shale, and siltstone units interbedded with thin layers of anthracite coal correspond to the representative range of major and minor element concentrations of the fugitive dust particles and overlie the predominant trends on chemical data plots for each element.

The results of this study provide strong evidence that the fugitive dust accumulations on surfaces around the homes and yards of residents in Lattimer, Pennsylvania most likely originated from the organic-rich silicate rocks that are actively being quarried and processed at the rock quarry operation to the north of the village. As a result of this research, news reports from Hazle Township indicate that the company that owns and operates the rock quarry north of Lattimer have implemented more effective dust control measures in order to be better neighbors.

\section{Acknowledgements}

The authors thank the residents of Lattimer, Pennsylvania for granting property access to collect fugitive dust samples and Mr. Andy Mehalshick for coordinating our sampling efforts. The present study was sponsored by the Department of Geology \& Physics and the Nanotechnology Program at Lock Haven University of Pennsylvania.

\section{References}

[1] Watson, J.G. and Chow, J.C., "Source characterization of major emission sources in the Imperial and Mexicali Valleys along the US/Mexico border," The Science of the Total Environment, 276, 33-47, 2001.

[2] Vega, E., Mugica, V., Reyes, E., Sánchez, G., Chow, J.C., and Watson, J.G., "Chemical composition of fugitive dust emitters in Mexico City,” Atmospheric Environment, 35, 4033-4039, 2001.

[3] Kim, K., Kabir, E., and Kabir, S., “A review on the human health impact of airborne particulate matter," Environmental International, 74, 136-143, 2015.

[4] Kong, S., Ji, Y., Lu, B., Chen, L., Han, B., Li, Z., and Bai, Z., "Characterization of $\mathrm{PM}_{10}$ source profiles for fugitive dust in Fushun-a city famous for coal,” Atmospheric Environment, 45, 5351-5365, 2011.
[5] Valavanidis, A., Fiotakis, K., and Vlachogianni, T., “Airborne particulate matter and human health: toxicological assessment and importance of size and composition of particles for oxidative damage and carcinogenic mechanisms," Journal of Environmental Science and Health Part C, 26, 339-362, 2008.

[6] Watson, J.G. and Chow, C., "Reconciling urban fugitive dust emissions inventory and ambient source contribution estimates: summary of current knowledge and needed research," DRI Document No. 6110.4F, Desert Research Institute, Reno, May, 2000.

[7] Shah, A.S.V., Langrish, J.P., Nair, H., McAllister, D.A., Hunter, A.L., and Donaldson, K., "Global association of air pollution and heart failure: a systematic review and meta-analysis,” The Lancet, 382, 1039-1048, 2013.

[8] Anderson, J.O., Thundiyil, J.G., and Stolbach, A., "Clearing the air: a review of the effects of particulate matter air pollution on human health,” Journal of Medical Toxicology, 8, 166-175, 2012.

[9] Davidson, C.I., Phalen, R.F., and Solomon, P.A., "Airborne particulate matter and human health: a review,” Aerosol Science and Technology, 39, 737-749, 2005.

[10] Gelencser, A., Kovats, N., Turoczi, B., Rostasi, A., Hoffer, A., Imre, K., Nyiro-Kosa, I., Csakberenyi-Malasics, D., Toth, A., Czitrovszky, A., Nagy, A., Nagy, S., Acs, A., Kovacs, A., Ferincz, A., Hartyani, Z., and Posfai, M., "The red mud accident in Ajka (Hungary): characterization and potential health effects of fugitive dust," Environmental Science \& Technology, 45, 1608-1615, 2011.

[11] Samet, J.M., Dominici, F., Curriero, F.C., Coursac, I., and Zeger, S.I., "Fine particulate air pollution and mortality in 20 US cities 1987-1994,” New England Journal of Medicine, 343, 1742-1749, 2000.

[12] Castranova, V. and Vallyathan, V., "Silicosis and coal workers" pneumoconiosis,” Environmental Health Perspectives, 108 (4), 675-684, 2000.

[13] Torres Rey, C.H., Pinilla, M.I., Ayala, L.B., Guerrero, D.M.C., Torres, G.M., Groot de Restrepo, H., and Uribe, M.V., "Underground coal mining: relationship between coal dust levels and pneumoconiosis, in two regions of Colombia, 2014,” BioMed Research International, Article ID 647878, 8 pg., 2015.

[14] Petsonk, E.L., Rose, C., and Cohen, R., "Coal mine dust lung disease, new lessons from an old exposure,” American Journal of Respiratory and Critical Care Medicine, 187 (11), 1178-1185, 2013.

[15] Berg, T.M., Edmunds, W.E., and MacLachlan, D.B., "Geologic Map of Pennsylvania," Commonwealth of Pennsylvania, Department of Environmental Resources, Bureau of Topographic and Geologic Survey, 1980.

[16] Rasband, W.S., "ImageJ," U.S. National Institutes of Health, Betheseda, Maryland, USA, https://imagej.nih.gov/ij/, 2016.

[17] Carr, M.J. and Gazel, E., "Igpet software for modeling igneous processes: examples of application using the open educational version,” Mineralogy and Petrology, 111, 283-289, 2017.

[18] Xu, T., Liu, J., Shi, Q., Niu, G., and Duan, Y., "Multi-elemental surface mapping and analysis of carbonaceous shale by laserinduced breakdown spectroscopy,” Spectrochimica Acta Part B, 115, 31-39, 2016.

[19] Caracciolo, L., Le Pera, E., Muto, F., and Perri, F., "Sandstone petrology and mudstone geochemistry of the Peruc-Korycany Formation (Bohemian Cretaceous Basin, Czech Republic),” International Geology Review, 53 (9), 1003-1031, 2011. 